\title{
El agregado de T3 a la sustitución con levotiroxina puede mejorar las funciones neurológicas y el estado anímico.
}

Effects of thyroxine as compared with thyroxine plus triiodothyronine in patients with hypothyroidism. Bunevicius R, Kazanavicius $G$, Zalinkevicius R. N Engl J Med. 1999; 340: 424-429

\section{Objetivo}

Comparar el efecto de la sustitución con levotiroxina con el de levotiroxina más triiodotironina (T3) sobre sistema nervioso y otras funciones en pacientes hipotiroideos.

\section{Diseño}

Ensayo clínico randomizado con seguimiento a 10 semanas.

\section{Lugar}

Instituto de Endocrinología, Universidad de Medicina, Kaunas, Lituania. Departamento de Psiquiatría, Facultad de Medicina, North Carolina.

\section{Pacientes}

31 mujeres y 2 varones, edad media (SD) $46+/-13$ años, con hipotiroidismo, 16 por tiroiditis autoinmune y 17 post tiroidectomía por cáncer tiroideo. Recibían levotiroxina en dosis sustitutivas los primeros e inhibitorias de TSH los segundos. Cuatro presentaban depresión mayor.

\section{Intervención}

Se estudió a cada paciente durante dos períodos consecutivos de 5 semanas. Durante un período recibía su dosis usual de levotiroxina. Durante el otro $50 \mu \mathrm{g}$ de esa dosis se reemplazaban por $12.5 \mu \mathrm{g}$ de triiodotironina. El orden en que cada grupo recibía los dos tratamientos fue randomizado.

\section{Medición de resultados principales}

Se definió como resultado principal al perfil psicológico evaluado por pruebas de función cognitiva, estado de ánimo y síntomas físicos. Se dosaron tiroxina (T4), triiodotironina (T3), tirotrofina (TSH) y globu- lina transportadora de esteroides sexuales (SHBG), de síntesis hepática inducida por hormonas tiroideas. Todos los parámetros fueron medidos basalmente y al final de cada período.

\section{Resultados principales}

La media de T4 fue menor y la de T3 mayor luego del tratamiento con levotiroxina más triiodotironina que con levotiroxina unicamente. La SHBG fue más alta en el grupo de terapia combinada, la TSH fue similar en ambos.

Entre las 17 pruebas de función cognitiva 6 fueron mejores luego del tratamiento con levotiroxina más triiodotironina, así como los resultados de 10 sobre 15 escalas analógicas para evaluar estado anímico y bienestar físico.

La frecuencia cardíaca fue mayor en el grupo de tratamiento combinado. No hubo diferencia entre las respuestas de los 4 pacientes con depresión con las de los 29 restantes. La mayoría de los pacientes refirió sentirse mejor al recibir levotiroxina más triiodotironina que al recibir levotiroxina unicamente.

\section{Conclusiones}

En pacientes hipotiroideos tratados con levotiroxina, la sustitución de parte de la dosis de levotiroxina por triiodotironina puede mejorar la función síquica y el estado de ánimo. La frecuencia cardíaca más elevada y el aumento de SHBG en los que recibían triiodotironina induce a pensar en el efecto directo de esta hormona en algunos tejidos.

Palabras claves: hipotiroidismo, levotiroxina, triiodotironina, función neurosicológica

\section{COMENTARIO}

La administración de triiodotironina sola o asociada a levotiroxina es seguida por un pico de absorción con elevación suprafisiológica de T3 y manifestaciones clínicas como taquicardia. Por su vida media breve se necesita más de una toma diaria. La levotiroxina tiene una cinética estable con escasa oscilación plasmática, que permite su administración en una única toma. Dado estos considerandos es que el tratamiento del paciente hipotiroideo con levotiroxina se impuso en forma universal, con excelentes resultados.

Según este estudio el uso de levotiroxina más triiodotironina es superior al de la levotiroxina sola, con mejoría del estado anímico y de la función cognitiva, con hormonas tiroideas y TSH séricas normales. Deben tomarse algunos recaudos al interpretar sus resultados: los puntos finales son pruebas de función psicológica y de estado de ánimo, difíciles de evaluar cuantitativamente a diferencia de otros parámetros como pruebas de función cardíaca o consumo de oxígeno. Es también conocido el tiempo de adecuación que necesitan los diferentes tejidos para estabilizar su concentración de T4 y T3. Los periodos de 5 semanas utilizados pueden ser insuficientes para alcanzar ese equilibrio luego de los cambios de dosis y del agregado de otra hormona. A su vez, el tiempo de "lavado" del tratamiento previo en este corto lapso se superpone a los efectos del esquema del período siquiente. Por último, teniendo en cuenta que la concentración de T3 alcanzada en corteza cerebral administrando unicamente levotiroxina a animales tiroidectomizados es normal independientemente del amplio rango de concentración de T4 sérica, es difícil de interpretar la mejoría relatada por los pacientes cuando reciben las dos hormonas asociadas.

Hechas estas salvedades, si bien es atractivo el tratamiento del paciente hipotiroideo con la combinación de levotiroxina y triiodotironina, remedando el estado fisiológico, la evidencia hasta ahora disponible no lo aconseja. Ya hemos comentado los niveles suprafisiológicos de T3 que ocurren luego del pico de absorción. Tampoco hay que olvidar que la combinación ideal de levotiroxina y triiodotironina todavía no existe, y que esta debería ser provista en forma de liberación lenta para evitar efectos cardíacos adversos. Hay que tener en cuenta que el tratamiento solo con levotiroxina se acerca mucho a la situación fisiológica en que el organismo produce T3 en las medidas de sus necesidades. Finalmente y por sobre todo, los pacientes sustituídos solamente con levotiroxina en dosis adecuadas, no solo no tienen quejas sino que relatan sensación de total bienestar.

\section{Dra. Carmen Cabezón}

Servicio de Endocrinología, Metabolismo y Medicina Nuclear. Hospital Italiano de Buenos Aires.

\section{Referencias}

1.Thyroxine Therapy. Toft A D. N Engl J Med 1994; 178: 174-180

2.Thyroid Hormone Treatment: When and What. Oppenheimer JH, Braverman L E, Toft A D. J Clin Endocrinol Metab 1995; 80: 2873-2883. 